\title{
Research on Optimizing Model for Logistics Location under Electronic Commerce based on Heuristic Algorithm
}

\author{
Xuqi Zhang \\ $X i^{\prime}$ an International University \\ Zhang eight North Road No. 408, Xi'an, Shanxi, China \\ 1020640555@qq.com
}

\begin{abstract}
With the development of the computer network technology and the etectronlc commerce, more and more firms establish the electronic sale channel and get great profits. The huge supply chain network is established through the new idea and technology. The node location selection is a planning process that chooses a location to set up a logistics node in an economy zone with multi demands. Hence, its location selection is a key link in the logistics system planning. In this paper, we consider the specific particularity of the e-commerce. Then, we constraints cost and delivery time of the logistics model. At last, we apply the heuristic algorithm to the location modes. The results show that the algorithm can apply to the logistics distribution problem under the electronic commerce environment excellently.
\end{abstract}

Keywords: Electronic Commerce, vehicle scheduling problem, time constraint

\section{Introduction}

With the rapid development of Internet and the information changing, the e-commerce makes an immense impact on the economic life. E-commerce represents the development direction of the future trade, and it will become the new economic mode in twenty-first century. However, the laggard logistics and distribution restrict the development of the electronic commerce in China. Many traditional logistics distribution systems are unable to adapt to the actual needs for the development of the electronic commerce. These systems become a bottleneck that hinders the development of the electronic commerce. Therefore, how to select the location and solve the vehicle routing problem become the key factor for establishing the efficient e-commerce distribution system under the electronic commerce. Solving the logistics distribution problem effectively under the electronic commerce will greatly reduces the logistics cost and the delivery time. It also guarantees the quality of service. This problem becomes an important issue that the logistics enterprises have to face under the electronic commerce.

Joel S. E. Teo, Eiichi Taniguchi, Ali Gul Quresh proposed a logistics measure for an urban road network in an e-commerce delivery system environment. Most notable contribution of this evaluation methodology is the combination of vehicle routing and scheduling problem with time window (VRPTW), auction theory and reinforcement learning in a multi-agent framework [1]. The results of the model show that Government-driven City Logistics measures has the potential of reducing truck emission when the administrator learns and prices the road links. Using data from online customer ratings, we explore how the relationships between logistics performance and customer loyalty are affected by risk characteristics of products and efficiencies of the websites. Ramakrishnan explored how the relationships between logistics performance and customer loyalty are affected by risk 
characteristics of products and efficiencies of the websites with the data from online customer ratings [2]. Wang Ying and Sang Dayong analyzed the relationships between the 3PL and supply chain members [3]. The authors suggested that only when the 3PL reengineers its logistics business process to accommodate the customer could it maximize the value of the customer. Markus Hesse thought the significance of electronic commerce (e-commerce) for freight transport, logistics and physical distribution, regarding both business to business and business to consumer commerce.

At present, scholars get many achievements about the researches of the distribution problem at home and abroad. From the division of the model and algorithm, this problem can be divided into the three main research directions. One is the model and algoritthm of the distribution center location model. Other one is the model and algorithm of the distribution path optimization problems. The last one is the model and algorithm of locating the vehicle routing problems. Among them, the typical research method of the continudus model uses the gravity method to solve the location problem of Euclidean distance which is proposed by Francis and White [5]. The research method of the discrete classical model is KuehnHamburger model [6], Baumyr Wolf method [7], the mixed integer progyamming method [8], Capacitated Facility Location method [9] and P-middle value problems [10]. The dynamic location model is to solve the facility location problem. We solve the problem from the angle of the demand and the cost across the time of the planning period. The model makes the total long-term cost minimum [11-12]. The stochastic model and its research methods are mainly divided into two categories. They are probability method and the scenario planning method. The system input parameters of these two methods are uncertain [13].

Due to the location problem of the logistics distribution center under the electronic commerce environment, the moder and the algorithm is complex. Thereby, we should not use the linear model to handle this problem, We use the heuristic algorithm to solve this problem. The structure of this paperis as follows. The first part of this paper is the introduction of the related problems. The second part is the establishment of the mode. The third part is the numerical analysis and the final partin the experiment.

\section{Establishment of the Model}

\subsection{The Related Conditions of Establishing the Model}

The decentralized location model needs the address sets of the demand points in a certain area. We select a certain number of alternative addresses from the address sets. We make the total costs of the logistics distribution system minimum between the logistics distribution center and each customer.

2.1. The Assumptions: (1) We only consider the distribution of one product. (2)The production capacity of the logistics enterprises can meet the customers' demand. (3)We only consider the new distribution center in a certain range of the options. (4)The distributed goods are delivered in one-time transportation. (5) A distribution center only supplies a client. (6) We count the customers' demand according to the regions. And we know the demanded quantity of the product for the customers. (7)The transportation cost of the distributed products is in direct ratio to the transport volume. (8)The fixed cost of the establishment and the operation is known, if a distribution center is selected. 
2.1.2. The Model Parameters: The specific parameters are as follows.

$N\left\{n_{i} \mid i-1,2, \ldots, N\right\}$ is the logistics enterprise node set at $N . M\left\{m_{i} \mid i-1,2, \ldots, M\right\}$ is the alternative distribution center node set at $M . K\left\{k_{i} \mid i-1,2, \ldots, K\right\}$ is the client node set at $K$. $C_{i j}$ is the freight unit for delivering the products from the logistics $i$ to the distribution center $j . C_{j k}$ is the freight unit for delivering the products from the distribution $j$ to the customer $k . f_{j}$ is the fixed operation cost of the distribution center $j . t_{i j}$ is the transportation time from the logistics enterprise $i$ to the distribution center $j \cdot t_{j k}$ is the transportation time from the distribution center $j$ to the customer $k . T_{k}$ is the required delivery time of ${ }^{\circ}$ the customer $k . W_{i j}$ is the transport volume for delivering the products from the logistics enterprise $i$ to the distribution center $j . W_{j k}$ is the transport volume for delivering the products from the distribution center to the customer $k$. As the unit price of the circulative goods. $c_{i}$ is the delivered quantity of the logistics enterprise $i$ ? $a_{k}$ is the demanded quantity of the customer $k . b_{j}$ is the capacity of the distribution center $j_{j} . p$ is the maximum of the alterative distribution centers.

2.1.3. The Decision Variables: If the distribution center is selected, the decision variable $Y_{j}=1$. Otherwise, $Y_{j}=0$. Amongthem, $j \in M Q$

\subsection{The Improvement Cost in the Location Model}

The location problem of the distribution center belongs to the minimum cost problem. Our goal is to minimize the total cost of the transportation cost, the operation cost and other cost. In generally, the objective function is as follows.

The total cost function=the fixed cost + the transportation cost + the variable cost

(1) The fixed cost

The fixed cost mainly uncludes the construction investments of the distribution center and the purchasing cost etc. This cost includes the depreciation cost of the buildings, the equipments and the madbineries. Once the distribution center is established, we must pay all of the fixed costs no matter the state of business is good or bad. $\sum_{j \in M} f_{j} Y_{j}$ is the fixed cost in the distribution center location model.

\section{(2) The transportation cost}

The transportation cost is the sum of two cost. One cost is for delivering the products from the logistics enterprises to the distribution centers. The other one is for delivering the products from the distribution centers to the customers. In order to unify the concepts, we combine the transportation cost with the delivery cost as the transportation cost. $\sum_{i \in N} \sum_{j \in M} C_{i j} W_{i j}+\sum_{i \in N} \sum_{j \in M} C_{j k} W_{j k}$ is the transportation cost in the decentralized distribution center location model.

\section{(3)The variable cost}

The variable cost is the management cost when we deliver the products in the distribution center. Most of the models view the variable cost as the linear function. This setting is not consistent with the actual situation and it is difficult to reflect the actual cost of the 
distribution center. Therefore, the setting makes a large difference between the optimal plan and the actual optimal condition. In the electronic commerce, the quantities of the products in one distribution batch are smaller, but the numbers of the transportation batches are more. The variable cost is not a linear function.

Therefore, we introduce an index $\lambda$ when we consider the variable cost in the electronic commerce. The index meets the condition $0<\lambda \leq 1$ in order to conform the actual logistics distribution. In addition, we change the original variable cost $\sum_{i \in N} \sum_{j \in M} \mu_{j} W_{i j}$ to $\sum_{i \in N} \sum_{j \in M} \mu_{j}\left(W_{i j}\right)^{\lambda}$ in order to conform the actual logistics distribution.

\section{3. Timing Constraint}

The development of the e-commerce raises a claim for logistics. One requirement is decreasing the cost and the other one is decreasing the delivery time. So, in the choice of the logistics model, we must consider the delivery time. The total time that delivering the products from the logistics enterprise to the distribution center and delivering the products from the distribution center to the customers should less than the time that the customers require. That is $\left(t_{i j}+t_{j k}\right) \cdot Y_{j} \leq Y_{k}, k \in K$.

\section{4. The Location Model}

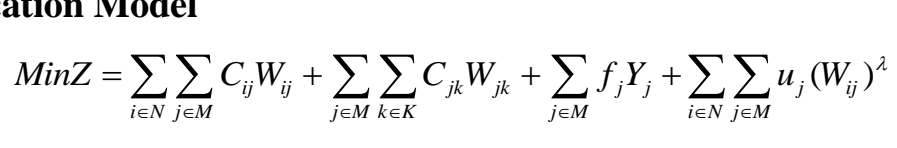

The constraint conditions

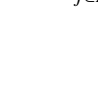

$$
\begin{gathered}
\sum_{i \in N} W_{i j} \leq b_{j} Y_{j}, j \in M \\
\left(t_{i j}+t_{j k}\right) \cdot Y_{j} \leq T_{k} k \in K \\
\sum_{j \in M} Y_{j} \leq p
\end{gathered}
$$$$
Y_{j}=0,1, j \in M
$$

In the formula (1), the objective function is to solve the transport cost. These transport costs include the cost for delivering the products from the logistics enterprise to the distribution center. In addition, they also include the minimum cost for delivering the products from the distribution center to the customer, the fixed cost and the variable cost of the distribution center. The constraint condition (2) is to ensure that the transport volume for delivering the products from the logistics enterprise to the distribution center which is below to the amounts of the supply. The constraint condition (3) ensures that the delivery quantity of the logistics enterprise can meet the customers' demand. The constraint condition (4) can assure the stocking requirement of the distribution center is less than the capacity of the distribution center. The constraint condition (5) ensures the input quantity of the distribution 
center is equal to the output quantity. The constraint condition (6) ensure that the sum of the transport time for delivering the products from the logistics enterprise to the distribution center and the transport volume for delivering the products from the distribution center to the customer is less than the distributive limited time about products for the customer. The constraint condition (7) ensures the number of the distribution center is not greater than the maximum number.

\subsection{The Heuristic Algorithm of the Distribution Center for the Location Model}

We consider that the constrain condition $\sum_{j \in M} Y_{j} \leq p$ is a constant in the improved model. We select the $p$ distribution center as the combination from the $M$ selected distroution centers. Therefore, there are $C_{m}^{p}$ combinations. We use $\xi$ to represent the set of alternative distribution centers which are in different combinations. The filtering step is as follows.

Step1 We calculate that there are $C_{m}^{p}$ combinations

Step2 For every combination, we calculate whether the combination meets the formula $\sum_{j \in \xi} W_{i j} \leq b_{j}(j \in \xi)$.

Step3 If the combination meets the formula, the combination is feasible. Otherwise, we reject the combination.

Step4 For the feasible combination which satisfies the Step2, we calculate whether the combination meets $\sum_{j \in b_{j}} \geq \sum_{k=k} a_{k}$. Amongthem, $j \in \xi$.

Step5 If the combination meets $\sum_{j \in \xi} b_{j} \geq \sum_{k \in K} a_{k}$, we can get the $T\left(T \leq C_{m}^{p}\right)$ sub problems.

\subsection{The Application Description of the Heuristic Algorithm in the Feasible Sub Problem}

Although each sub problem is still a nonlinear programming problem, the number of variables and constraint conditions has reduced greatly. The problem does not contain 0-1 variables any longer. The solving steps of the heuristic are as follows.

Step/After using the filter conditions, we get the $T$ feasible combinations. We take a combination randomly from the above feasible combinations.

Step2 We calculate the feasible combination for the initial solution. The solution require that the freight minimum relatively between the logistics enterprise and the customer $(i, k)$. That is, the sum of the freight $C_{i j}$ delivered from the logistics enterprise to the distribution center and the freight $C_{j k}$ delivered from the distribution center to the customer are minimum.

$$
Z_{i k}^{0}=\min \left(C_{i j}+C_{j k}\right)=\left(C_{i j}^{0}+C_{j k}^{0}\right), j \in T
$$

In all $(i, k)$, we select the minimum cost $Z_{i k}^{0}$. The sets which meet (10) are $I^{t}$. The number of the initial distribution center is $I_{0}$. 


$$
I^{t}=\left\{j \mid \min \left[C_{i j}+C_{j k}\right], j \in T\right\}
$$

Step3 If we know the production capacity and the demand of the logistics enterprise, we use the most constrained conditions to solve the transportation problem. For all of the $j \in I^{t}$, we make the cost function minimum.

$$
\operatorname{MinZ}=\sum_{i \in N} \sum_{j \in I^{t}} C_{i j} W_{i j}+\sum_{j \in I^{t}} \sum_{k \in K} C_{j k} W_{j k}
$$

The constraint equation is as follows.

Now we get the initial optimal solution.

$$
\begin{gathered}
\sum_{j \in I^{t}} W_{j k} \geq a_{k}, \quad k \in K \\
\sum_{i \in N} W_{i j}=\sum_{k \in K} W_{j k}, j \in I^{t} \\
\sum_{j \in I^{t}} W_{i j} \leq c_{i}, i \in N \\
W_{i j} \geq 0, W_{j k} \geq 0, i \in N, i \in I^{t}, \hat{N} \in K
\end{gathered}
$$$$
y_{i j}=W_{i k}^{0}, i \in \mathbb{C}
$$

Step4 We get the handling capacitlof the distrabution center is as follows.

$$
W_{\wedge}^{0} \subseteq \sum_{k \in K} W_{j k}^{0}, j \in I^{t}
$$

We verify the relationship between the handling capacity and the maximum capacity $b_{j}$ of the distribution center. We need to testify whether $W_{j}^{0} \leq b_{j}$. If this formula holds up, we continue to the next step. Otherwise, the feasible solution will be replaced. Then we need to return to step2.

Step5 We calculate Whether $\left(t_{i j}+t_{j k}\right) \cdot Y_{j} \leq T_{k}, k \in K$ is established. If this formula holds up, we proceed to the next step. Otherwise, the feasible solution is to be replaced. Then, we return to the step2.

Step6 We calculate the variables costs from the throughput of the distribution center in return.

$$
z_{i k}^{n}=\min \left[C_{i j}+C_{j k}+\mu_{j} \lambda\left(W_{j}^{n-1}\right)^{\lambda-1}\right]
$$

This formula is the partial differential for the objective function. In this stage, $j \in I^{t}$. We calculate the following formula for all of the $(i, k)$.

$$
z_{i k}^{2}=\min \left[C_{i j}+C_{j k}+\mu_{j} \lambda\left(W_{j}^{0}\right)^{\lambda-1}\right]
$$

In the formula, the number of the logistics distribution center $I^{2}$ is corresponding to $z_{i k}^{2}$. We make the cost function (12) is the minimum by this foundation again. And we get the second optimal solution.

$$
W_{i j}^{2}=W_{j k}^{2}, j \in I^{t}
$$


Step7 We calculate whether $\left(t_{i j}+t_{j k}\right) \cdot Y_{j} \leq T_{k}, k \in K$ is established. If this formula holds up, we proceed to the next step. Otherwise, the feasible solution is to be replaced. Then we return to the step2.

Step8 We calculate the $n$ times solution. We assume that the optimal solution is $W_{i j}^{n-1}=W_{j k}^{n-1}, j \in I^{t}$ of $n-1$ tines. We calculate the throughput of the distribution center is $W_{j}^{n-1}=\sum W_{j k}^{n-1}$. Among them, $j \in I^{t}$. For all of the $(i, k)$, we calculate the following formula.

$$
z_{i k}^{n}=\min \left[C_{i j}+C_{j k}+\mu_{j} \lambda\left(W_{j}^{n-1}\right)^{\lambda-1}\right]
$$

In the formula, the number of the logistics distribution center $I^{n}$ is corpesponding to $z_{i k}^{n}$. We make the cost function (12) is the minimum by this foundation again. And we get the $n$ times optimal solution. $W_{i j}^{n}=W_{j k}^{n}, j \in I^{t}$

Step9 We compare the $n-1$ times throughput of the distribution center $W_{j}^{n-1}$ with the $n$ times throughput of the distribution center $W_{j}^{n}$. If theyare equal, we stop the calculation. If they are not equal, we need to calculate repeatedly until $W_{j}^{n-1}=W_{j}^{n}$. Then we get the optional solution $W_{i j}^{n}=W_{j k}^{n}, j \in I^{t}$.

Step10 We repeat the steps from the second to the ninth. And we calculate the optimal solution for the rest sub feasible problems. ${ }^{\circ}$

Step11 We compare the optimal solution of 'each feasible sub problem and get the minimum cost. That is, we obtain the optimal sólution.

\section{The Example Analysis}

A company has two factories $A_{1}$ and $A_{2}$. These two factories supply products to the eight areas. There is a distribution station delivering the products door to door in each area $\left(B_{1}, B_{2}, B_{3}, B_{4}, B_{5}, B_{6}, B_{7}, B_{8}\right)$. Now there are five candidate sites of the distribution centers $D_{1}, D_{2}, D_{3}, D_{4}$ and $D_{5}$. We should choose several distribution center to make the total distribution cost minimum. In this paper, we need to consider the economic scale. That is, the distribution cost and the throughput of the products have a nonlinear relationship. The known conditions are shown in table 1 , table 2 and table 3 . We make $p=0.5$.

\section{(1)The initial solution}

For all of the combination from the factory to the distribution station, we need to find the distribution center which makes the add cost of the transportation cost and the distribution minimum. $D_{j}$ indicates the distribution center that the products go through. The initial transport problem shows in table.7.

(2)The second solution 
We can find out the throughput $W_{j}^{0}$ of each candidate site by using the initial solution. We calculate the throughput of the distribution center $W_{j}^{0}=\sum_{k \in K} W_{j k}^{0}$. The data are shown in table. 8 and table.9. We select the minimum value of the transportation cost, the distribution cost and the variable cost for all of the combination from the factory to the distribution station. The corresponding route is the least cost flow path. Now we get the second solution, and we can see it in table 10 .

(3)The third solution

We can calculate the throughput $W_{j}^{1}$ of each candidate site by using the second solution. Then we can get variable cost. Due to $D_{2}$ and $D_{5}$ have no throughput, we assume the variable costs of $D_{2}$ and $D_{5}$ are $M(M \rightarrow \infty)$. The data are shown in Table 11 , Table 12 and Table 13.

Table 1. The Transport Unit Cost from the Factory to the Candidate Site of the Distribution Center

\begin{tabular}{cccccccc}
\hline The candidate site & $D_{1}$ & $D_{2}$ & $D_{3}$ & $D_{y}$ & $D_{5}$ & Supply \\
\hline$A_{1}$ & 5 & 10 & 20 & & 40 & 45 & 100 \\
$A_{2}$ & 25 & 13 & 7 & 15 & 17 & 200 \\
\hline
\end{tabular}

Table 2. The Variable Cost forthe Candidate Site of the Distribution Center

\begin{tabular}{|c|c|c|c|}
\hline The candidate site & $D_{1}$ & $\overline{D_{4}}$ & $\overline{D_{5}}$ \\
\hline The fixed cost & 650 & 680 & 750 \\
\hline The variable cost & $00 W_{1}^{p} \times 600 W_{2}^{p}$ & $200 W_{4}^{p}$ & $200 W_{5}^{p}$ \\
\hline
\end{tabular}

Table 3. The Unit Distribution Cost from the New Candidate Site to each Distribution Station

\begin{tabular}{|c|c|c|c|c|c|c|c|c|}
\hline $\begin{array}{l}\text { The distribution } \\
\text { station }\end{array}$ & 8 & $B_{2}$ & $B_{3}$ & $B_{4}$ & $B_{5}$ & $B_{6}$ & $B_{7}$ & $\begin{array}{l}B_{8} \\
\end{array}$ \\
\hline$\overline{D_{1}}$ & 12 & 5 & 13 & 22 & 30 & 46 & 41 & 50 \\
\hline$D_{2}$ & 50 & 13 & 5 & 10 & 17 & 33 & 27 & 37 \\
\hline & 34 & 22 & 10 & 5 & 9 & 25 & 19 & 29 \\
\hline & 58 & 46 & 33 & 25 & 16 & 5 & 9 & 9 \\
\hline & 59 & 50 & 37 & 29 & 17 & 9 & 18 & 5 \\
\hline domand & 20 & 30 & 80 & 40 & 60 & 30 & 20 & 20 \\
\hline
\end{tabular}

Table 4. The Minimum Transport Cost

\begin{tabular}{ccccccccc}
\hline $\begin{array}{c}\text { The distribution } \\
\text { station }\end{array}$ & $B_{1}$ & $B_{2}$ & $B_{3}$ & $B_{4}$ & $B_{5}$ & $B_{6}$ & $B_{7}$ & $B_{8}$ \\
\hline & $\left(D_{1}\right)$ & $\left(D_{1}\right)$ & $\left(D_{2}\right)$ & $\left(D_{2}\right)$ & $\left(D_{2}\right)$ & $\left(D_{2}\right)$ & $\left(D_{2}\right)$ & $\left(D_{2}\right)$ \\
$A_{1}$ & 17 & 10 & 15 & 20 & 27 & 43 & 37 & 47 \\
& $\left(D_{1}\right)$ & $\left(D_{2}\right)$ & $\left(D_{3}\right)$ & $\left(D_{3}\right)$ & $\left(D_{3}\right)$ & $\left(D_{4}\right)$ & $\left(D_{4}\right)$ & $\left(D_{6}\right)$ \\
$A_{2}$ & 37 & 26 & 17 & 12 & 16 & 20 & 24 & 22 \\
\hline
\end{tabular}


Table 5. Transportation Time Form Logistics Company to Distribution Center

\begin{tabular}{cccccc}
\hline The candidate site & $D_{1}$ & $D_{2}$ & $D_{3}$ & $D_{4}$ & $D_{5}$ \\
\hline$A_{1}$ & 5 & 6 & 3 & 4 & 7 \\
$A_{2}$ & 6 & 5 & 4 & 3 & 6 \\
\hline
\end{tabular}

Table 6. Time from Distribution to Customer and Customer's Time Requirement

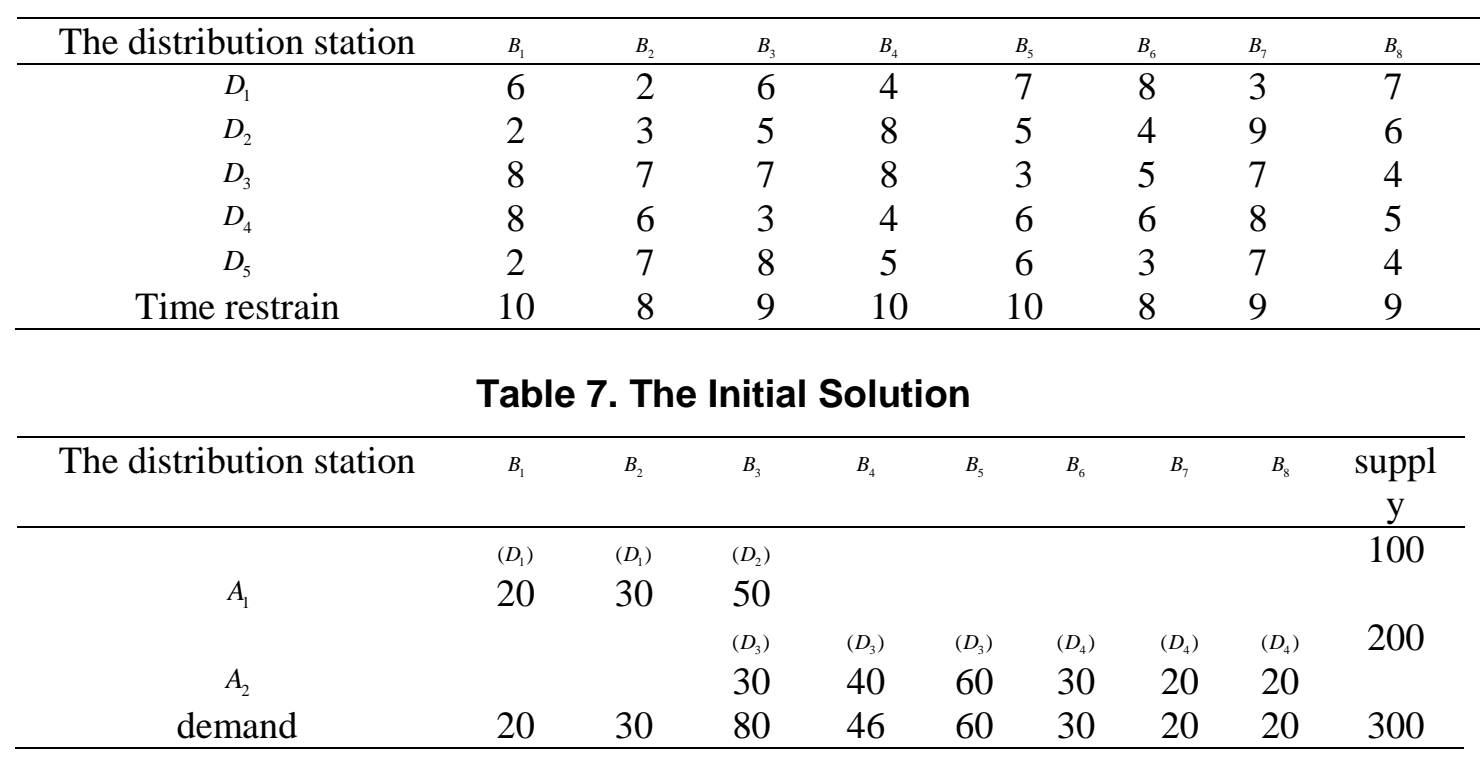

We adjust the initialosolution accordikg to the time restrain $\left(t_{i j}+t_{j k}\right) \cdot Y_{j} \leq Y_{k}, k \in K$.

After this adjusting, wealculate the throughput of the distribution center $W_{j}^{0}=\sum_{k \in K} W_{j k}^{0}$.

Table 8. The Test throughput and the Variable Cost of the Distribution Center

\begin{tabular}{cccccc}
\hline The candidate site & $D_{1}$ & $D_{2}$ & $D_{3}$ & $D_{4}$ & $D_{5}$ \\
\hline The throughput & 50 & 50 & 130 & 50 & 20 \\
The variable cost & $150 / 50^{p}=21.2$ & $300 / 75^{p}=42.4$ & $250 / 130^{p}=21.9$ & $100 / 50^{p}=14.2$ & $100 / 20^{p}=22.4$
\end{tabular}

Table 9. The Minimum Transport Cost based on Flexible Cost and Time Restrain

\begin{tabular}{ccccccccc}
\hline $\begin{array}{c}\text { The distribution } \\
\text { station }\end{array}$ & $B_{1}$ & $B_{2}$ & $B_{3}$ & $B_{4}$ & $B_{5}$ & $B_{6}$ & $B_{7}$ & $B_{8}$ \\
\hline & $\left(D_{1}\right)$ & $\left(D_{1}\right)$ & $\left(D_{1}\right)$ & $\left(D_{3}\right)$ & $\left(D_{3}\right)$ & $\left(D_{4}\right)$ & $\left(D_{3}\right)$ & $\left(D_{4}\right)$ \\
$A_{1}$ & 38.2 & 31.2 & 39.2 & 46.9 & 50.9 & 59.2 & 60.9 & 63.2 \\
& $\left(D_{1}\right)$ & $\left(D_{3}\right)$ & $\left(D_{3}\right)$ & $\left(D_{3}\right)$ & $\left(D_{3}\right)$ & $\left(D_{4}\right)$ & $\left(D_{4}\right)$ & $\left(D_{4}\right)$ \\
$A_{2}$ & 58.2 & 50.9 & 38.9 & 33.9 & 37.9 & 34.2 & 38.2 & 38.2 \\
\hline
\end{tabular}

According to the time restrain, we choose the total cost minimum and the transport route is the best. We get the second solution. 
Table 10. The Second Solution

\begin{tabular}{cccccccccc}
\hline $\begin{array}{c}\text { The distribution } \\
\text { station }\end{array}$ & $B_{1}$ & $B_{2}$ & $B_{3}$ & $B_{4}$ & $B_{5}$ & $B_{6}$ & $B_{7}$ & $B_{8}$ & supply \\
\hline & $\left(D_{1}\right)$ & $\left(D_{1}\right)$ & $\left(D_{1}\right)$ & & & & & & 100 \\
$A_{1}$ & 20 & 30 & 50 & & & & & & \\
& & & $\left(D_{3}\right)$ & $\left(D_{3}\right)$ & $\left(D_{3}\right)$ & $\left(D_{4}\right)$ & $\left(D_{4}\right)$ & $\left(D_{4}\right)$ & 200 \\
$A_{2}$ & & & 30 & 40 & 60 & 30 & 20 & 20 & \\
demand & 20 & 30 & 80 & 46 & 60 & 30 & 20 & 20 & 300 \\
\hline
\end{tabular}

We consider the fixed coat and make the number of distribution center minimum. So the ${ }^{\bullet}$ total cost is minimum.

Table 11. The Second throughput and the Variable Cost of the Distribution Center

\begin{tabular}{cccccccc}
\hline the candidate site & $D_{1}$ & $D_{4}$ & $D_{5}$ \\
\hline The throughput $W_{j}^{1}$ & 100 & & & \\
\hline
\end{tabular}

We calculat the variable expense of the distribution station by the throughput of the distribution station.

\section{(1) Table 13. The Third Solution}

\begin{tabular}{lccccccccc}
\hline The distributionstation & $B_{1}$ & $B_{2}$ & $B_{3}$ & $B_{4}$ & $B_{5}$ & $B_{6}$ & $B_{7}$ & $B_{8}$ & supply \\
\hline & $\left(D_{1}\right)$ & $\left(D_{1}\right)$ & $\left(D_{1}\right)$ & & & & & & 100 \\
& 20 & 30 & 50 & & & & & & \\
& & & $\left(D_{3}\right)$ & $\left(D_{3}\right)$ & $\left(D_{3}\right)$ & $\left(D_{4}\right)$ & $\left(D_{4}\right)$ & $\left(D_{4}\right)$ & 200 \\
$A_{2}$ & & & 30 & 40 & 60 & 30 & 20 & 20 & \\
demand & 20 & 30 & 80 & 40 & 60 & 30 & 20 & 20 & 300 \\
\hline
\end{tabular}

From the table 11, we can see that the throughput of the third solution is equal to the second solution. Therefore, the third solution is the final solution. From the final solution we can see we select $D_{1}, D_{2}$ and $D_{3}$ to establish the distribution center in the five candidate sites.

\section{Conclusion}

With the continuous development of Internet technology and information technology, more and more enterprises sell products through the network channels. However, the laggard 
logistics in our country restricts seriously the development of the electronic commerce, especially the facility problem and the delivery problem. Therefore, more and more scholars begin to study the logistics distribution problems under the electronic commerce environment.

In this paper, we apply the heuristic algorithm to the logistics distribution problem under the electronic commerce environment. The algorithm coincides the time and it can remove the unfeasible condition. The results show that the algorithm can apply to the logistics distribution problem under the electronic commerce environment excellently.

\section{References}

[1] J. S. E. Teo, E. Taniguchi and A. G. Quresh, "Evaluating city logistics measure in e-commerce wilh multiagent systems", Procedia - Social and Behavioral Sciences, vol. 29, (2012), pp. $349-359 \lambda$

[2] R. Ramanathan, "The moderating roles of risk and efficiency on the relationship between logistics performance and customer loyalty in e-commerce", Transportatión Research Part E. Logistics and Transportation Review, vol. 46, no. 6, (2010), pp. 950-962.

[3] W. Ying and S. Dayong, "Multi-agent framework for third partylogisties in E-commerce", Expert Systems with Applications, vol. 29, no. 2, (2005), pp. 431-436.

[4] M. Hesse, "Shipping news: the implications of electronic commerce for logistics and freight transport", Resources, Conservation and Recycling, vol. 36, no. 3, (2002), pp. 211-240.

[5] R. L. Francis and J. A. White, "Facility layout and location: an analytical approach", Prentice Hall, Englewood Cliff, NJ, (1974).

[6] P. Hansen and N. Mladenovic, "Variable neighborhood search for the p-median", Location Science, vol. 5, (1997), pp. 207-226

[7] J. Da-yuan, "Study on Location Selection based on Multi-Node Logistics", Railway transport and economy, vol. 27, no. 8, (2005), pp. 24-26.

[8] A. B. Masood, "Combining the ahalytic hierarchy process and goal programming for global facility locationallocation problem", International Joumal of Production Economics, vol. 62, no. 2, (1999), pp. 237-248.

[9] D. J. Gong, M. S. Gen and G. F. Yamazaki "Hybrid evolutionary method for capacitated location-allocation problem", Computers Industrial Engineering, vol. 33, no. 3, (1997), pp. 577-580.

[10] C. H. Aikens, "Facility Location Models for Distribution Planning", European Journal of Operational Research,1985, vol. 22, no, 2, pp. 263-279.

[11] M. Frantzeskakis and C. D. T. Naston-Gandy, "The use of state space relaxation for the dynamic facility location problem Amals of operations research, vol. 18, (1989), pp. 189-212.

[12] A. Shulman, "An Algorithm for solving dynamic capacitated plant location problems with discrete expansion sizes", Operations research, vol. 39, no. 3, (1991), pp. 423-436.

[13] O. Berman and D. Krass, "Facility Location with Stochastic Demand and Congestion", In Drezner Z, Hamacher H.W. (Eds), Facility Location: Applications and Theory, Berlin, Springer, (2001).

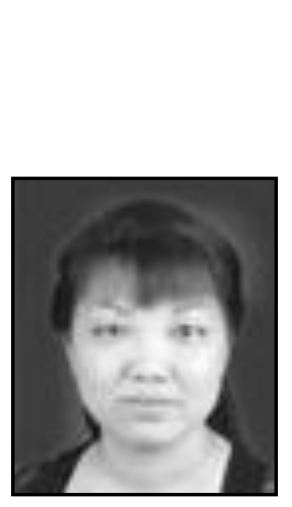

\section{Author}

Xuqi Zhang, Female, she was born in Xian on November 7th, 1968. She received her bachelor's Degree in Chemistry (1991) from Northwest University and in 2005 she began to engage in teaching logistics. She also got MBA from Hongkong economic and Trade University. Now she is employed in Xi'an international university, working on logistics management research, and also the head of logistics Department in Xi' an international university. 
International Journal of Multimedia and Ubiquitous Engineering Vol.9, No.6 (2014)

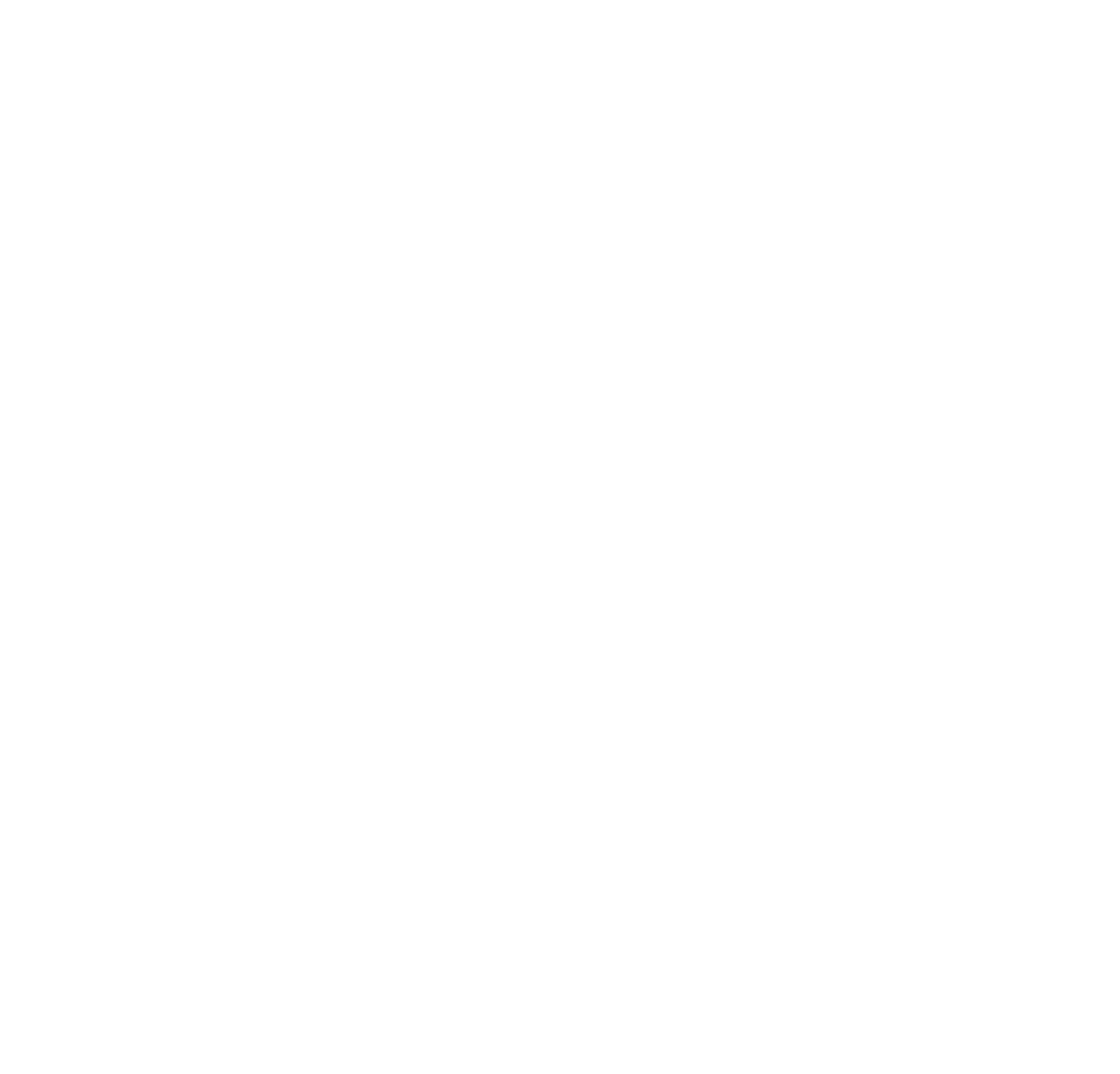

